\title{
Sensitivity analysis of atmospheric spectral irradiance model
}

\author{
André Albino ${ }^{1, *}$, Daniele Bortoli ${ }^{1}$, Mouhaydine Tlemçani $^{1}$, Abdeloawahed Hajjaji ${ }^{2}$, \\ and António Joyce ${ }^{3}$ \\ ${ }^{1}$ Institute of Earth Sciences, University of Évora \\ ${ }^{2}$ Science Engineer Laboratory for Energy (LabSIPE), National School of Applied Sciences, University of Chouaib \\ Doukkali, Morocco \\ ${ }^{3}$ Energy Laboratory, Solar Energy Unit National Laboratory of Energy and Geology
}

Received: 13 May 2019 / Received in final form: 27 June 2019 / Accepted: 15 July 2019

\begin{abstract}
Many radiative transfer models (RTM) have been developed to simulate and estimate solar irradiance. Its accuracy is well documents in literature nonetheless the effect of uncertainties of the parameters on the established model has not been well studied yet. This work focuses on implementing an RTM based on the models found in the literature along with some updates, with the aim to study the sensitivity of the model towards the inputs parameters. The parameters study in this paper are: the Day of year, the Solar zenith angle, the Local atmospheric pressure, the Local temperature, the Relative humidity, the Height of ozone layer concentration, the ozone concentration, the single scattering albedo, the Ground albedo, the Ångström's exponent and the aerosol optical depth. The sensibility analysis is achieved by using the Normalized Root Mean Square Error (NRMSE) as an objective function, calculated with a set of simulated measurements of spectral global solar irradiance and a reference spectrum generated with a group of standard input parameters.
\end{abstract}

\section{Introduction} Solar irradiance spectrum is important in many fields of life sciences (human health, atmospheric sciences, energy). One of the common features of these sciences topics is to perform studies aiming to quantify the uncertainties of the measured solar irradiance [1,2]. The first step to assess these measurements errors is the use of a Radiative transfer models (RTM) to simulate spectral irradiance for a set of atmospheric representative parameters and boundary conditions. Many RTMs have been developed, some of them can be found in [3,4], a couple of commonly used are libradtran [5] and SMART [6]. RTMs are used for providing information when measurements are not available, to predict the weather conditions, to help with spectral information in calibrations [7] and to retrieve atmospheric proprieties $[8,9]$. The accuracy of the RTMs is documented in several studies $[3,4,10,11]$. Nevertheless, few of them take in account the effect of input uncertainties on the output result [12-16].

This work implements a simple RTM and performs the sensitivity analysis of the implemented model towards each of the input parameters. The model's parameters evaluated are: the day of the year $(n)$, solar zenith angle $(\theta)$, local atmospheric pressure $(P)$, local temperature $(T)$, relative humidity $(\mathrm{RH})$, height of ozone layer concentration $\left(z_{3}\right)$, ozone concentration $\left(\mathrm{C}_{\mathrm{O}_{3}}\right)$, single scattering albedo $\left(w_{0}\right)$, ground albedo $\left(\rho_{g}\right)$, Ångström's exponent $(\alpha)$ and the aerosol optical depth (AOD). This paper seeks to

e-mail: aalbino@uevora.pt analyses the effect of uncertainties on model inputs in the spectral global radiation estimated by the RTM to better understand the response of the model. Contrasting with the previous published works [12-16] referring to a specific region or country, this work uses simulated data with the aim of analyzing the RTM and its response regardless to a specific region. Using real data, the uncertainty depends on all the inputs and the sensors used to measure the parameters, while in simulation uncertainty over each input parameter can be controlled. The analysis is done only one parameter at each time, in order to assess the effect of each one. If all the input parameters are analyzed grouped it should be quite impossible to understand the effect of each one. Results contribute also to show the importance of the measure quality of each parameter.

This study is divided into five sections including this introduction. The next section presents the radiative transfer model and its parameters, followed by methodology presentation where the sensitive analysis of each parameter is explained. The fourth section presents and analyses the results obtained. In the finally section the conclusions are introduced.

\section{Radiative transfer model}

In this work the implementation of a RTM based on the algorithm established by Iqbal [17] is presented.

The flowchart of the model is depicted in Figure 1. This RTM simulates irradiance for cloudless sky and generates direct, diffuse and global spectral irradiance. 


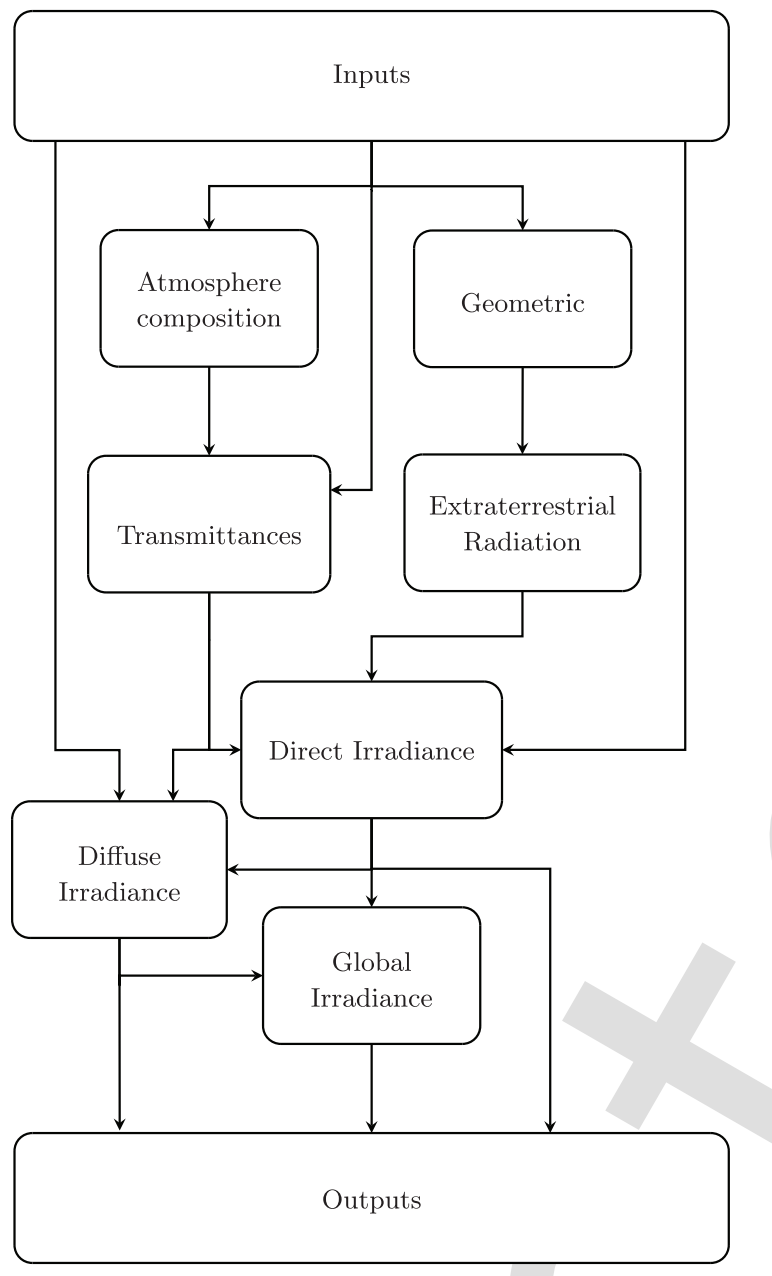

Fig. 1. Simplified flowchart of the radiative transfer model.

In the geometric part of the RTM, the eccentricity of the earth's orbit is calculated by $[15,17]$

$$
\epsilon=1+0.033 \cos \left(\frac{2 \pi n}{365}\right) .
$$

With the equation (1), extraterrestrial solar spectral irradiance $\left(I_{0 n}\right)$ can be corrected to the specific day. For the atmospheric composition, the relative optical air mass, the relative optical water-vapor mass and the relative optical ozone mass are estimated.

Regarding the atmospheric transmittances, the Rayleigh scattering, the diffusion of uniformly mixed gases, water-vapor and ozone are estimated. The aerosol transmittance is retrieved using Ångström's turbidity formula. All the transmittances are united in a transmittance due to the combined effects of continuum attenuation and molecular absorption $\left(\tau_{\lambda}\right)$ and used to calculate the spectral direct solar irradiance on the horizontal surface by the Beer-Lambert-Bouguer Law [17]

$$
I_{d \lambda}=I_{0 n} \tau_{\lambda} \cos (\theta)
$$

Finally, the components diffuse and global, of solar irradiance are calculated.
Table 1. Inputs parameters used by radiative transfer model.

\begin{tabular}{lll}
\hline Symbol & Name & Unit \\
\hline$n$ & Day of year & {[]} \\
$\theta$ & Solar zenith angle & {$\left[{ }^{\circ}\right]$} \\
$P$ & Local atmospheric pressure & {$[\mathrm{kPa}]$} \\
$w$ & Precipitable water & {$[\mathrm{cm}]$} \\
$z_{3}$ & Height of ozone layer concentration & {$[\mathrm{km}]$} \\
$C_{O_{3}}$ & Ozone concentration & {$[\mathrm{DU}]$} \\
$w_{0}$ & Single scattering albedo & {[]} \\
$\rho_{g}$ & Ground albedo & {[]} \\
$\alpha$ & Angström's exponent & []$]$ \\
$\beta$ & Angström's turbidity coefficient & {[]} \\
\hline
\end{tabular}

Using the interpolation method, different wavelength step can be used. Some parts of the model were updated using different data and more detailed equations from recent studies [18-20]. Extraterrestrial Solar Spectral Irradiance was modified using the data from Gueymard [18]. The ozone attenuation coefficients are replaced with the cross-section of ozone determined by by Bogunil et al. [19]. The equation presented by Frohlich and Shaw for Rayleigh optical depth (ROD) [20], was also used:

$$
\mathrm{ROD}=-0.00838 \lambda^{-3.916-0.074 \lambda-\frac{0.050}{\lambda}}
$$

where $\lambda$ is the wavelength in $\mathrm{nm}$. The RTM use ten inputs to describe the atmospheric state, present in Table 1.

Some of the considered quantities are difficult to measure or to obtain. However, they can be estimated using other proprieties: in this work we estimated the values for the precipitable water $(w)$ and the Ångström's turbidity coefficient $(\beta)$. This is done using the equation of Leckner $[17,21]$ which is based on the local temperature $(T)$ and the relative humidity $(R H)$

$$
w=\frac{0.493 \times R H \times p_{s}}{T}
$$

where $p_{s}$ is the partial pressure of water vapor in saturated air and is given by

$$
p_{s}=\exp \left(26.23-\frac{5416}{T}\right)
$$

The Ångström's turbidity coefficient can be calculated from Angström's Law [4], knowing the Ångström's exponent and the aerosol optical depth (AOD) at one wavelength $\left(\lambda_{0}\right)$

$$
\beta=A O D_{\left(\lambda_{0}\right)} \lambda_{0}^{\alpha}
$$

\section{Methodology}

To study the effect of the input parameters uncertainty on the established model, a set of inputs is fixed in order to be the standard parameters values, this values are present in Table 2. Their application to the model generates a standard spectral irradiance (Istd) starting in $0.325 \mu \mathrm{m}$ and finish at $1.075 \mu \mathrm{m}$ with a step of $1 \mathrm{~nm}$. Following this 
Table 2. Standard input values

\begin{tabular}{ll}
\hline Input parameter & Value \\
\hline$n$ & 182 \\
$\theta$ & $45^{\circ}$ \\
$P$ & $101 \mathrm{kPa}$ \\
$T$ & $25^{\circ} \mathrm{C}$ \\
$R H$ & $50 \%$ \\
$z_{3}$ & $20 \mathrm{~km}$ \\
$C_{O_{3}}$ & $300 \mathrm{DU}$ \\
$w_{0}$ & 0.5 \\
$\rho_{g}$ & 0.5 \\
$\alpha$ & 1.5 \\
$A O D_{\left(\lambda_{0}\right)}$ & 0.1 \\
$\lambda_{0}$ & $0.675 \mu \mathrm{m}$ \\
\hline
\end{tabular}

step, the selected parameters are sequentially modified. Pressure $(P)$, temperature $(T)$, Height of ozone layer concentration $\left(z_{3}\right)$, Ozone concentration $\left(C_{O_{3}}\right)$, Ångström's exponent $(\alpha)$ and Aerosol optical depth (AOD) range from $50 \%$ to $150 \%$ of the standard values with a step of $0.01 \%$. In the rest of the parameters, all their range has analyzed. Single scattering albedo $\left(w_{0}\right)$ and Ground albedo $\left(\rho_{g}\right)$ change between 0 and 1, Relative humidity (RH) between 0 and $100 \%$, Solar zenith angle range from 0 to $90^{\circ}$ and the Day of year from 1 to 365 . Using these new values, the output of the model $(I)$ is evaluated 1000 times, generating a new set of solar irradiances. White noise is added to this set, in order to produce a more realistic simulation measurements of solar radiation. The used white noise has mean value sets at zero and standard deviation of $1 \%$. With the new obtained irradiance values, the normalized root mean square error (NRMSE) is calculated as shown in equation (7)

$$
\mathrm{NRMSE}=100 \frac{\sqrt{\frac{\sum\left(I_{s t d}-I\right)^{2}}{n}}}{\max (I)-\min (I)} .
$$

The mean and standard deviation values of NRMSE of each parameter is calculated and plotted versus the normalized variation of the parameter. Through the plots, the sensitivity of the model to each parameter can be observed, i.e., if an error on the input parameter occurs, it is reflected by an increase or decrease in the output of the model. The used standard input values are shown in Table 2. The global solar irradiance spectrum generated by the RTM with standard values is present in Figure 2.

\section{Results}

This section presents the plots of NRMSE for each input parameter. The first parameter analyzed is the day of year, present in Figure 3. The influence of the day of year on the model has been observed, is possible to see the seasonality of irradiance. The day chosen to be the standard value for the day of year was 182 - July 1 -, it is in the beginning of summer. The nearest days have showed a small error - $0.75 \%$ - and, in oppose, the higher error $-4.83 \%$ - was detected in the winter, like expected.

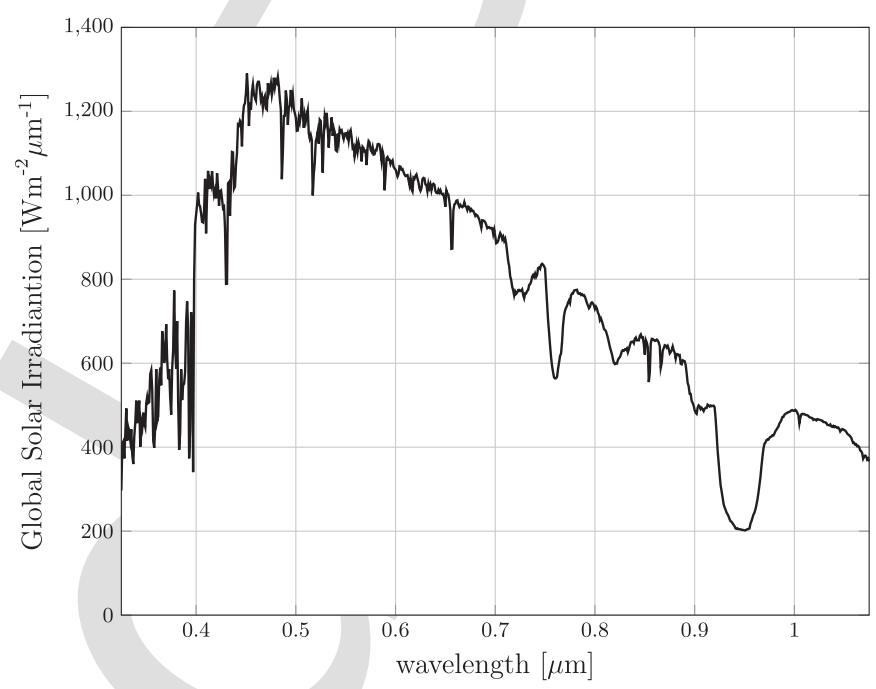

Fig. 2. Simulated global solar radiation spectrum generated with the radiative transfer model in the standard condition present in Table 2. The spectrum range from 0.325 to $1.075 \mu \mathrm{m}$ with a step of $1 \mathrm{~nm}$.

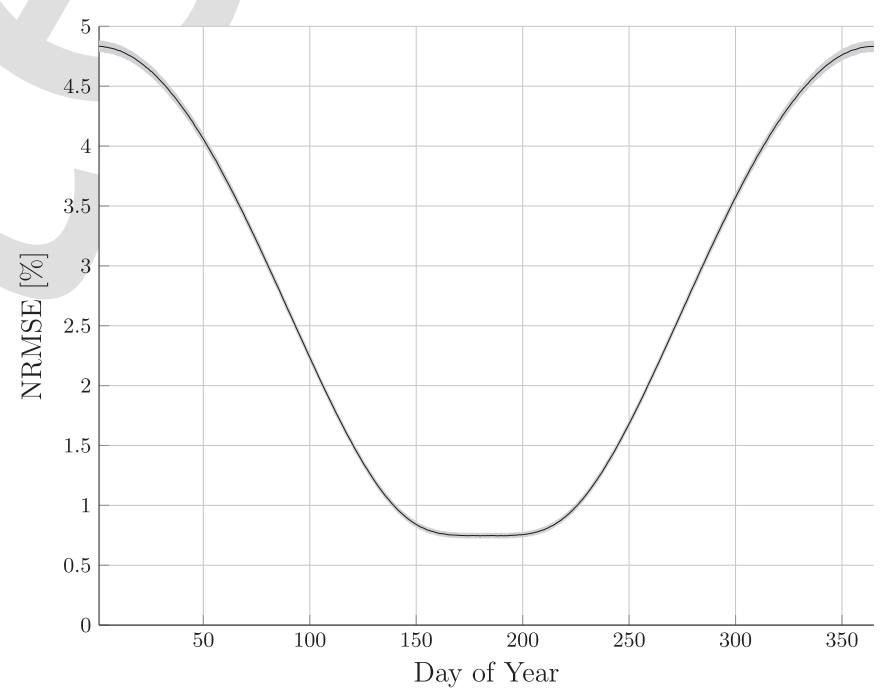

Fig. 3. Mean value (line) and standard deviation (gray area) of Normalized Root Mean Square of the output of the model with the day of year.

The standard deviation of NRMSE (gray area in plot) increase with distance of the standard value of the day of year.

The next analyzed parameter is the solar zenith angle $(\theta)$, which can be seen in Figure 4. This is the most influencer parameter on the model. When the $\theta$ is $90^{\circ}$ the mean error go to $567 \%$ with a standard deviation of $3.4 \%$. On the other hand, when $\theta$ go to $0^{\circ}$ the error is small than the previous - stay $22 \%$ - with a deviation of $0.18 \%$. Even so the highest error cause by a inputs parameter of model. The main reason for this error is the influence of solar zenith angle in the estimation of relative optical air mass. The relative optical air mass is estimated by the formulation of Kasten (Eq. (8)) [17] which present a 


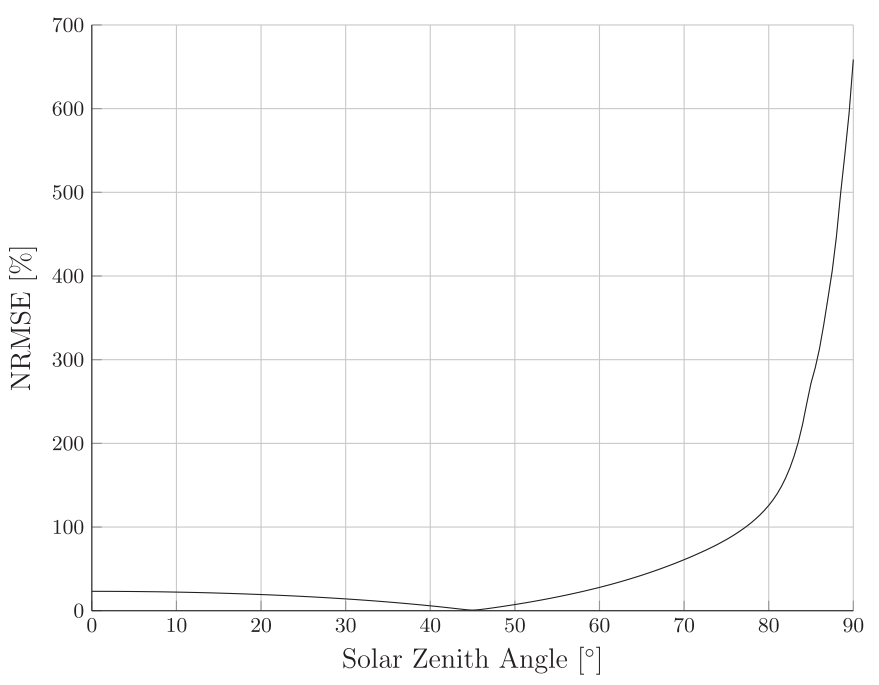

Fig. 4. Mean value (line) and standard deviation (gray area) of Normalized Root Mean Square of the output of the model with the solar zenith angle.

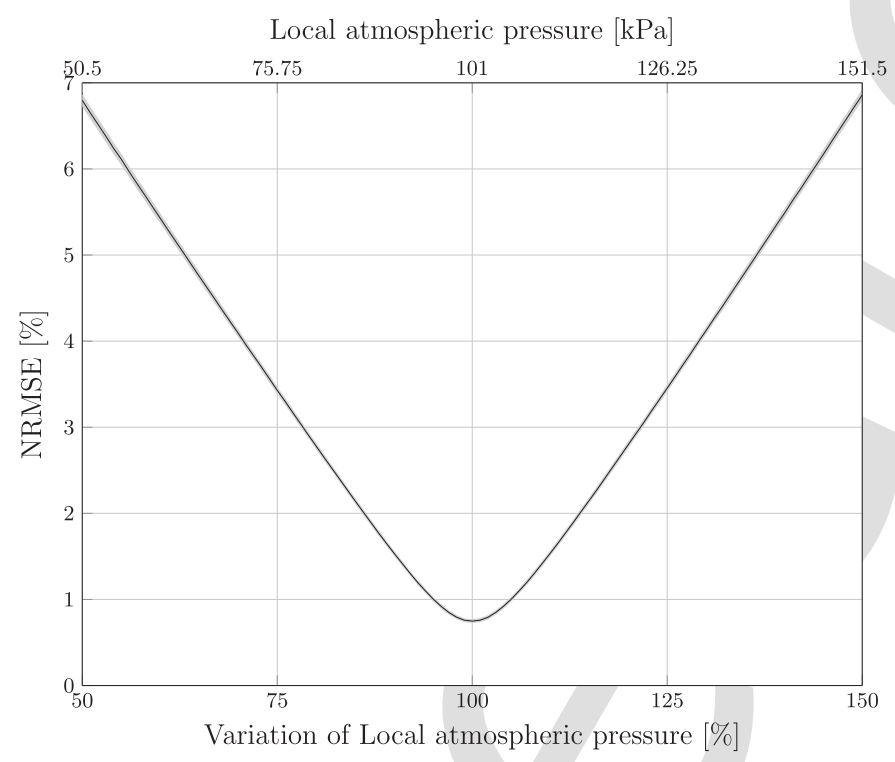

Fig. 5. Mean value (line) and standard deviation (gray area) of Normalized Root Mean Square of the output of the model. In the lower axis the local atmospheric pressure variation is present in percentage while in the upper axis this presents the local atmospheric pressure in $\mathrm{kPa}$.

significant error for angles greater than $86^{\circ}$.

$$
\left.m_{r}=\left[\cos \theta+0.15(93.885-\theta)^{-1.253}\right)\right]^{-1} .
$$

The local atmospheric pressure shown in Figure 5, presents a symmetric NRMSE, i.e., nearly the same error on both sides of the standard pressure value regardless of if the variation is to greater or lower values. The error increases until near $7 \%$ at the boundary values. It can also be noticed that the standard deviation value increases with the distance to the reference value, from $0.02 \%$ to $0.08 \%$.

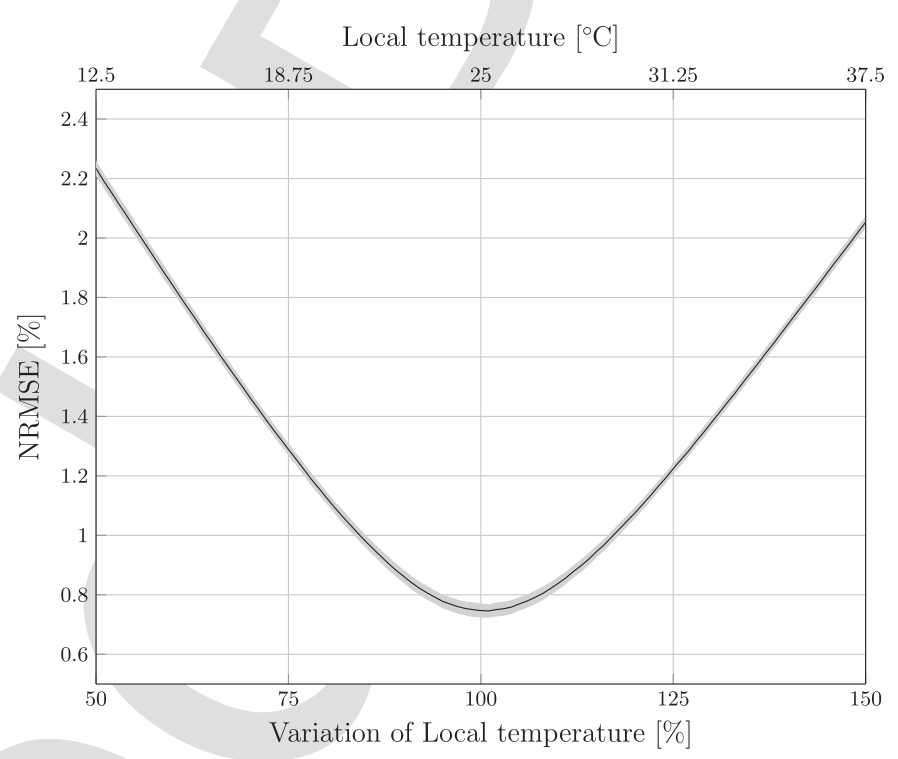

Fig. 6. Mean value (line) and standard deviation (gray area) of Normalized Root Mean Square of the output of the model. In the lower axis the local temperature variation is present in percentage while in the upper axis this presents the local temperature in ${ }^{\circ} \mathrm{C}$.

Almost symmetric is the error on the output of the model generated by the local temperature, as can be seen in Figure 6. To the highest temperature study $\left(37.5^{\circ} \mathrm{C}\right)$ mean error is $2.05 \%$, a little lower than error to the smallest temperature $\left(12.5^{\circ} \mathrm{C}\right) 2.23 \%$. The standard deviation of the NRMSE present a small negative correlation with temperature. The standard deviation of the error is $0.02 \%$ at the $25{ }^{\circ} \mathrm{C}$.

The next parameter to be analyzed is the relative humidity, and all range was study. The reference value used is $50 \%$ and in Figure 7 can be see that an error to a dry condition is almost $7 \%$. To moist condition the mean error is three and half times less, around $2 \%$. Standard deviation follow the similar shape, higher to dry and smaller to moist condition.

The curve of the height of ozone layer concentration, in Fig. 8, shows that the model is almost not influenced by this parameter. The change in the mean value of the NRMSE is very small. In this case the noise can be more important than the variation of the parameter

The effect of the Ozone concentration on the model is depicted in Figure 9. In this plot, it can be seen that an error of $50 \%$ in the input ozone concentration relatively to the standard value - $300 \mathrm{DU}$ - will produce an approximative NRMSE of $1.3 \%$. Also the plot show a shape of the NRMSE is very symmetric. This curve denote that this parameter does not have a "preferential side", i.e., the NRMSE varies the same way on either side of the standard value. The error in output increases with the error in input as expected. The standard deviation also increases with the input error, its value at standard ozone concentration is $0.02 \%$ and increase to $0.03 \%$.

The next parameter to be analyzed is the single scattering albedo. The maximum error is near $10 \%$ when the parameter go to zero. The standard deviation follows the 


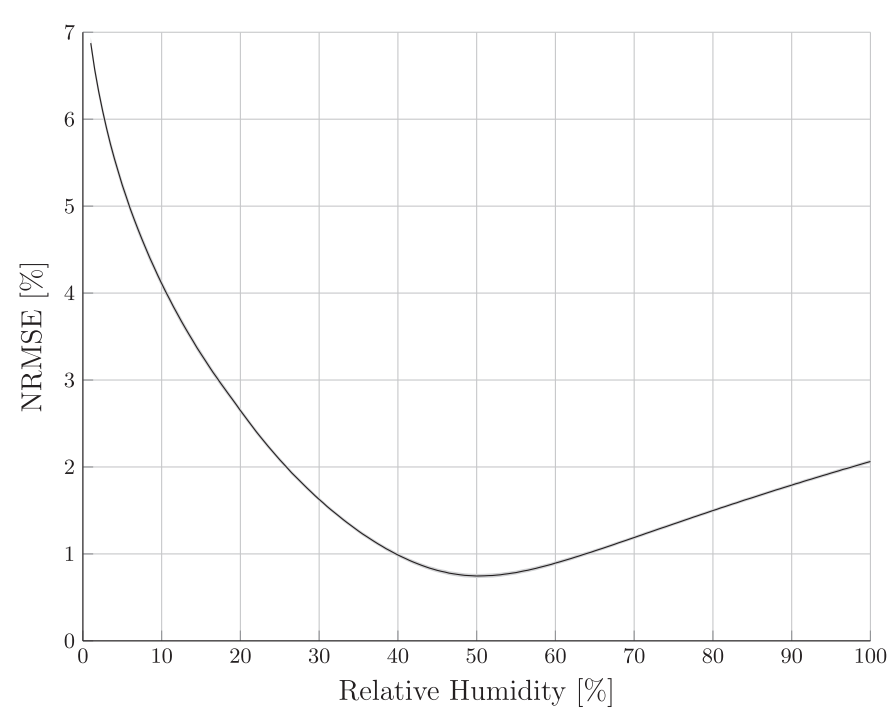

Fig. 7. Mean value (line) and standard deviation (gray area) of Normalized Root Mean Square of the output of the model with the variation of the relative humidity.

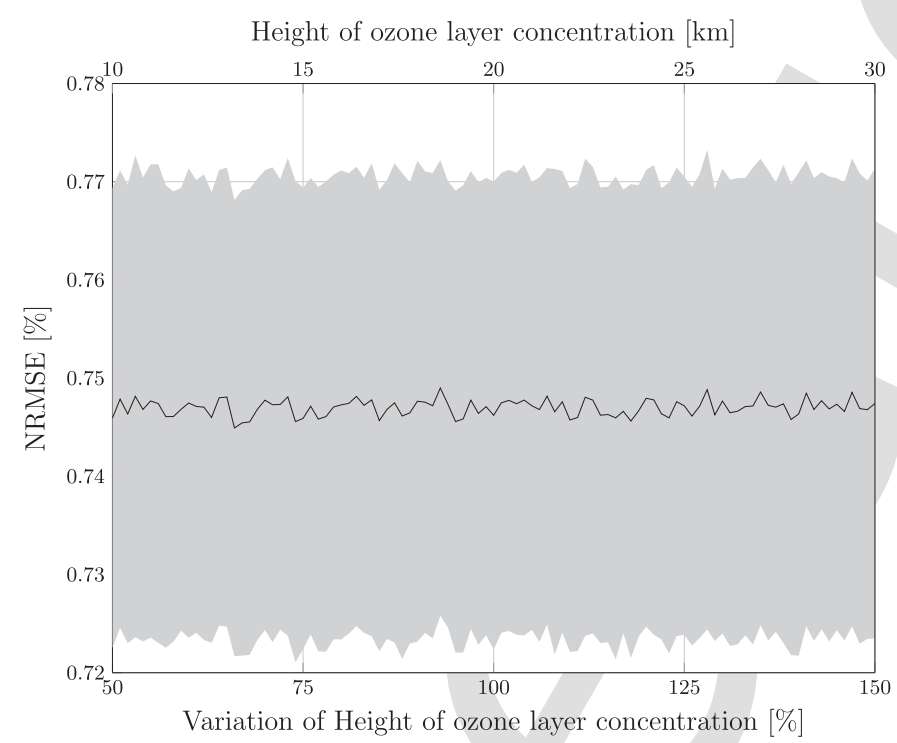

Fig. 8. Mean value (line) and standard deviation (gray area) of Normalized Root Mean Square of the output of the model. In the lower axis the variation of heigth of ozone layer concentration in percentage is presents while in the upper axis this presents the heigth of ozone layer concentration in $\mathrm{km}$.

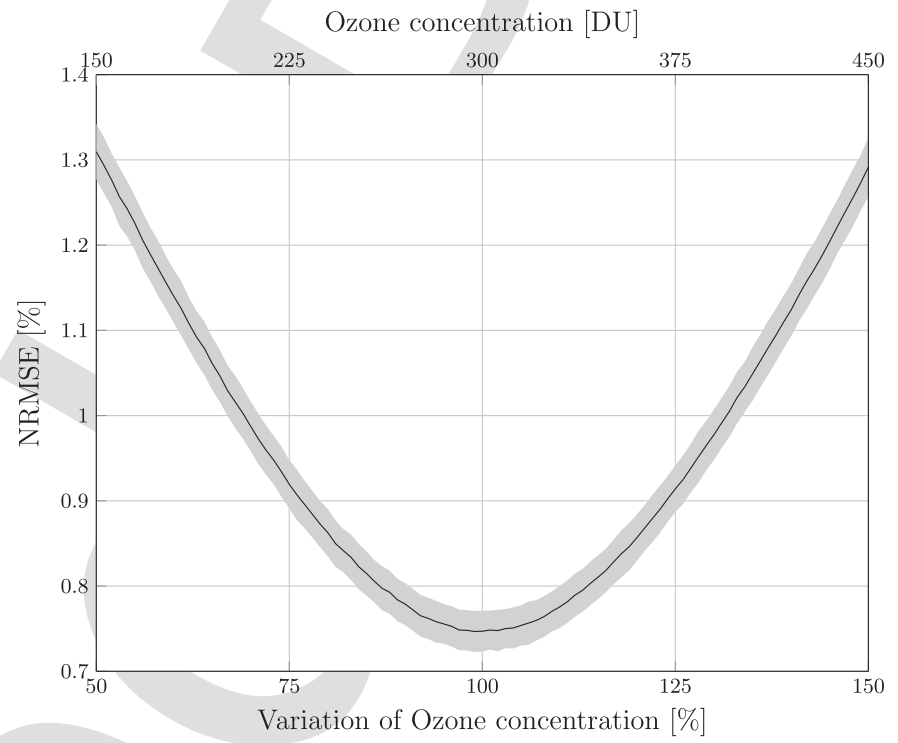

Fig. 9. Mean value (line) and standard deviation (gray area) of Normalized Root Mean Square of the output of the model. In the lower axis the ozone concentration variation is present in percentage while in the upper axis this presents the Ozone concentration in DU.

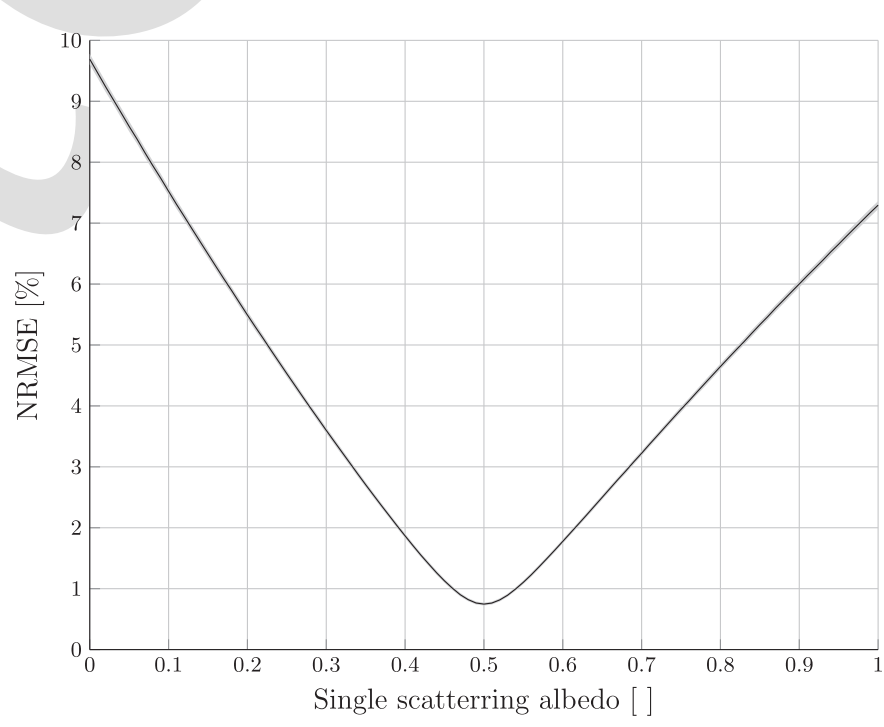

Fig. 10. Mean value (line) and standard deviation (gray area) of Normalized Root Mean Square of the output of the model with the variation of the single scattering albedo.

Figure 12 presents the NRMSE in function of the variation of the Angström's exponent. It is visible that, to an Ångström's exponent of 2.25 , NRMSE will be around $3 \%$. To other side to a variation of $50 \%$ of the standard value -1.5 - the mean value is higher than $2 \%$. This parameter is more responsive to variations to values higher than the standard value of the Ångström's exponent. Relatively to the standard deviation, it is, also, increasing faster to the higher value of the parameter analyzed and slower to the smaller value.

Finally, the last parameter to study, is the aerosol optical depth at the $0.675 \mu \mathrm{m}$ wavelength. The aerosol optical 


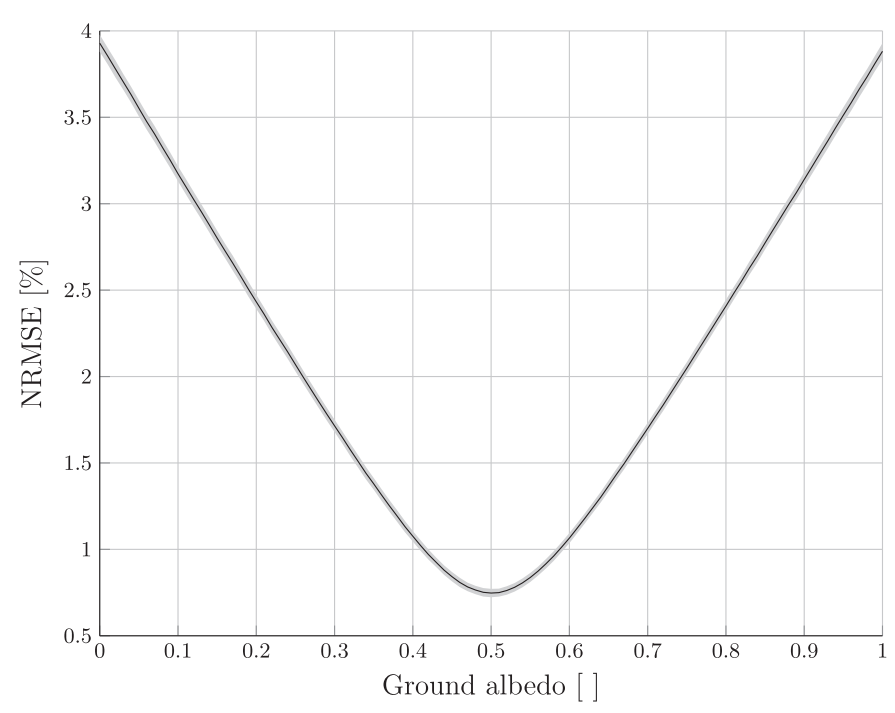

Fig. 11. Mean value (line) and standard deviation (gray area) of Normalized Root Mean Square of the output of the model with the variation of the ground albedo.

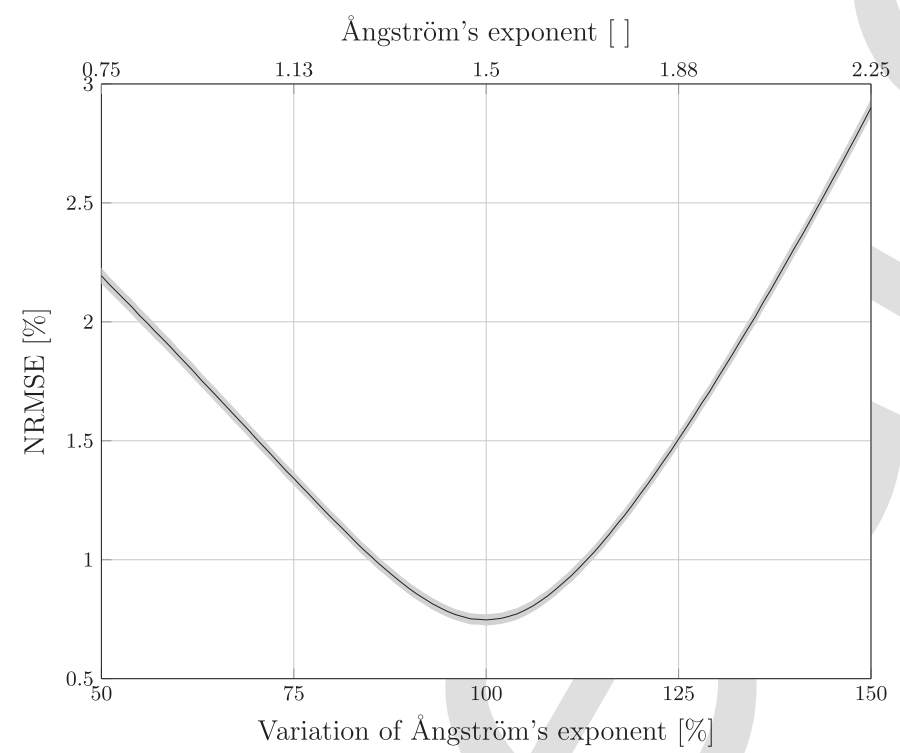

Fig. 12. Mean value (line) and standard deviation (gray area) of Normalized Root Mean Square of the output of the model. In the lower axis the Angström's exponent variation is present in percentage while in the upper axis this presents the Ângström's exponent.

depth generates similar mean NRMSE to higher and lower values of the parameter than the standard value -0.1 . The higher value of the mean NRMSE is around $3.6 \%$ to the extreme values, and the lowest value $-0.75 \%$ - at the standard value. Standard deviation are very symmetric present values near $0.05 \%$ to the range limits and $0.02 \%$ to the standard values.

\section{Conclusion}

The analysis performed in this work allows to see the influence of the errors and uncertainties of the input

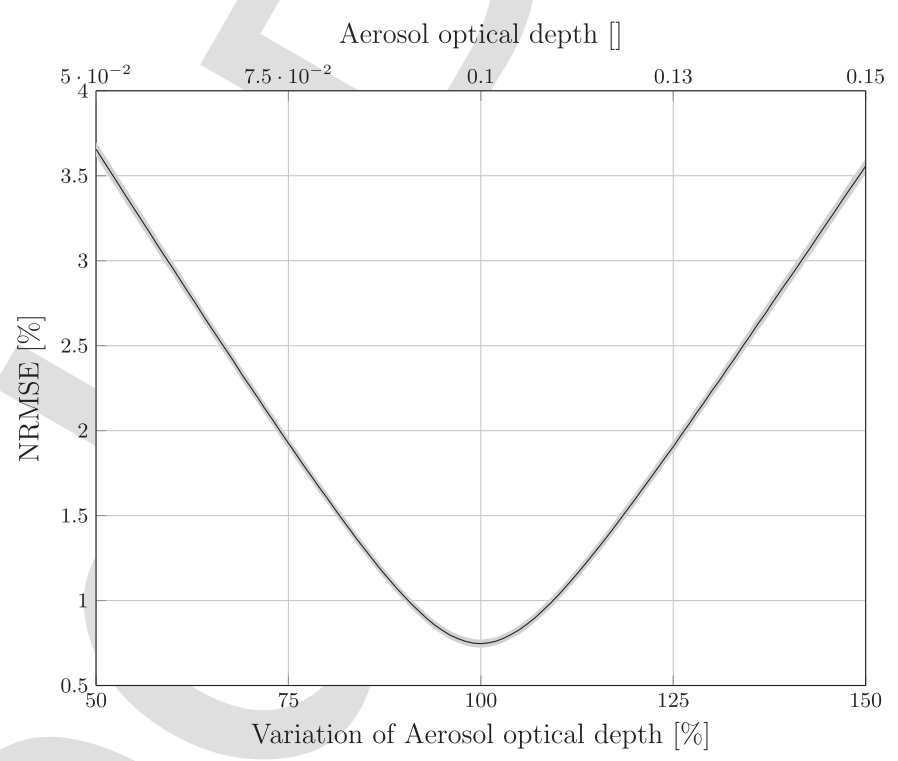

Fig. 13. Mean value (line) and standard deviation (gray area) of Normalized Root Mean Square of the output of the model. In the lower axis the variation of aerosol optical depth at the 0.675 $\mu \mathrm{m}$ is present in percentage while in the upper axis this presents the aerosol optical depth at the $0.675 \mu \mathrm{m}$

parameters on the output of the radiative transfer model. This study shows that the main parameters which influence the output of the model are the solar zenith angle with an error higher of $600 \%$, the local single scattering albedo with an error near $10 \%$ and with near $7 \%$ mean error the local atmospheric pressure and the relative humidity. In part, the error cause in the model output by solar zenith angle can be explained by the formulation of Kasten to relative optical air mass and its error to large angles. More information can be withdrawal from this study. Using the obtained graphs, it can now be possible to approximate the initial parameters knowing if they should be underestimated or overestimated. This analysis also shows that the height of ozone layer concentration can be used as a constant, one time that its error is always equal.

A. Albino gratefully acknowledges the financial support of "Fundação para a Ciência e Tecnologia" (FCT - Portugal), through the Doctoral Grant SFRH/BD/108484/2015. The work is co-funded by the European Union through the European Regional Development Fund, included in the COMPETE 2020 (Operational Program Competitiveness and Internationalization) through the ICT project (UID/GEO/04683/2013) with the reference POCI - $01-0145$ - FEDER - 432007690.

\section{References}

1. A. Albino, R. Salgado, M. Tlemçani, D. Bortoli, A. Joyce, in International Conference 9th Spanish-Portuguese Assembly of Geodesy and Geophysics, Madrid, Spain, 2016 (2016)

2. A. Albino, D. Bortoli, M. Tlemcani, A. Joyce, in International Conference on Advanced Materials for Photonics, 
Sensing and Energy Applications, Agadir, Morrocos, 2017 (2017)

3. J. Ruiz-Arias, C.A. Gueymard, Sol. Energy 171, 474 (2018)

4. V. Badescu, C.A. Gueymard, S. Cheval, C. Oprea, M. Baciu, A. Dumitrescu, F. Iacobescu, I. Milos, C. Rada, Renew. Energy 55, 85 (2013)

5. B. Mayer, A. Kylling, Atmos. Chem. Phys. 5, 1855 (2005)

6. F.C. Seidel, A.A. Kokhanovsky, M.E. Schaepman, Atmos. Meas. Tech. 3, 1129 (2010)

7. G. Hülsen, J. Gröbner, Appl. Opt. 23, 5877 (2007)

8. O. Dubovik, M.D. King, J. Geophys. Res. 105, 20673 (2000)

9. R. Román, J. Bilbao, A. de Miguel, J. Geophys. Res. Atmos. 119, 4690 (2014)

10. D.R. Myers, Energy 30, 1517 (2005)

11. S. Ding et al., J. Quant. Spectrosc. Radiat. Transf. 112, 1050 (2011)
12. G. Belluardo, G. Barchi, D. Baumgartner, M. Rennhofer, P. Weihs, D. Moser, Sol. Energy 132, 558 (2016)

13. R. Román, J. Bilbao, A. de Miguel, J. Quantit. Spectr. Radiat. Transfer 145, 95 (2014)

14. R. Román, J. Bilbao, A. de Miguel, Atmos. Environ. 89, 556 (2014)

15. J. Bilbao, R. Román, C. Yousif, D. Mateos, A. de Miguel, Atmos. Environ. 99, 508 (2014)

16. A. de Miguel, D. Mateos, J. Bilbao, R. Román, Atmos. Res. 102, 136 (2011)

17. M. Iqbal, An introduction to solar radiation, (Academic Press, 1983)

18. C.A. Gueymard, Sol. Energy 169, 434 (2018)

19. K. Bogumil, et al, J. Photochem. Photobiol. A 157, 167 (2003)

20. C. Fröhlich, G.E. Shaw, Appl. Opt. 19, 1773 (1980)

21. B. Leckner, Sol. Energy 20, 143 (1978)
283

284

285

286

287

Cite this article as: André Albino, Daniele Bortoli, Mouhaydine Tlemçani, Abdeloawahed Hajjaji, António Joyce, Sensitivity analysis of atmospheric spectral irradiance model, Eur. Phys. J. Appl. Phys. Vol, No (2019) 